This item was submitted to Loughborough's Research Repository by the author.

Items in Figshare are protected by copyright, with all rights reserved, unless otherwise indicated.

\title{
Maternal and paternal controlling feeding practices with male and female children
}

PLEASE CITE THE PUBLISHED VERSION

http://dx.doi.org/10.1016/j.appet.2006.04.002

PUBLISHER

(C) Elsevier

VERSION

AM (Accepted Manuscript)

LICENCE

CC BY-NC-ND 4.0

REPOSITORY RECORD

Blissett, Jacqueline, Caroline Meyer, and Emma Haycraft. 2019. "Maternal and Paternal Controlling Feeding Practices with Male and Female Children". figshare. https://hdl.handle.net/2134/11327. 
This item was submitted to Loughborough's Institutional Repository (https://dspace.lboro.ac.uk/) by the author and is made available under the following Creative Commons Licence conditions.

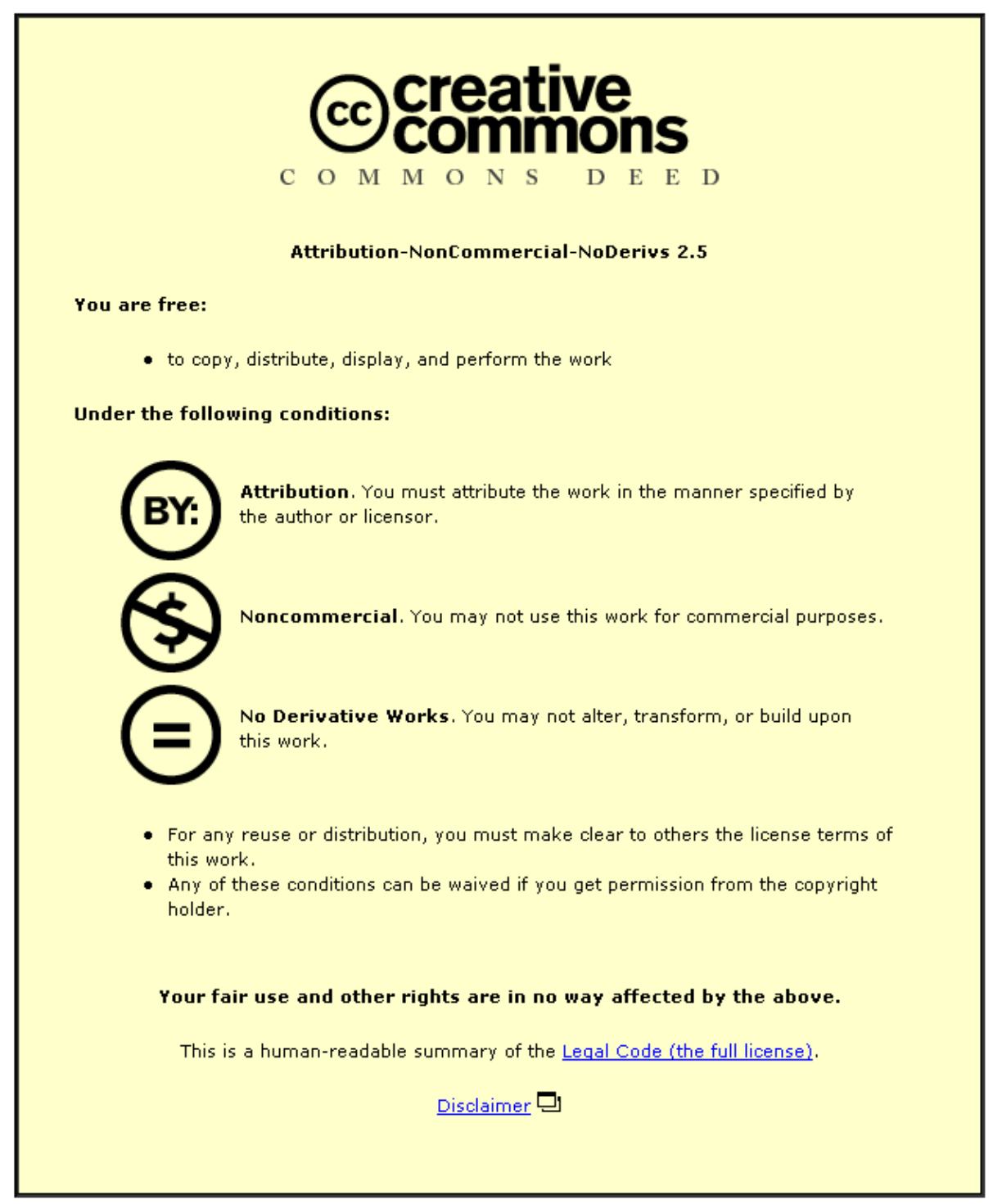

For the full text of this licence, please go to: http://creativecommons.org/licenses/by-nc-nd/2.5/ 


\title{
MATERNAL AND PATERNAL CONTROLLING FEEDING PRACTICES WITH MALE AND FEMALE CHILDREN.
}

\author{
Jacqueline Blissett ${ }^{\mathrm{a}}$ \\ Caroline Meyer ${ }^{\mathrm{b}}$ \\ Emma Haycraft ${ }^{\mathrm{a}}$ \\ ${ }^{a}$ School of Psychology, University of Birmingham, Edgbaston, \\ Birmingham, UK, B15 2TT. \\ bepartment of Human Sciences, Loughborough University, Loughborough, \\ Leicestershire, UK
}

Acknowledgements:

Rosa Chillari \& Wendy Pettitt

for their help in data collection

Address all correspondence to Dr. J. Blissett, School of Psychology, University of Birmingham, B15 2TT, UK.

Email j.blissett@bham.ac.uk, Tel 44 (0)121 4143340 Fax 44(0)121 4144897

Running Head: maternal and paternal feeding... 


\begin{abstract}
This study aimed to compare maternal and paternal feeding practices with male and female children and examine the influence of the gender of both the parent and child on the relationship between parental unhealthy eating attitudes and controlling feeding practices. One hundred and eighty eight participants (94 co-habiting mother-father dyads, mean age 36.4 years, $S D=4.9)$, who were the parents of 46 male and 48 female children (mean age 37.7 months, $\mathrm{SD}=12.7$ ) completed measures of unhealthy eating attitudes and feeding practices. Mothers and fathers differed significantly in their reports of unhealthy eating attitudes but not in their restrictive or pressurising feeding practices. Mothers reported greater perceived feeding responsibility and greater monitoring of their children's food intake than fathers. Bulimia scores were correlated with controlling feeding practices in mothers of girls but not boys. Fathers' body dissatisfaction was correlated with monitoring of sons' but not daughters' food intake. These findings suggest that parental extrapolation of weight concerns may be more likely to occur within mother-daughter and father-son relationships.
\end{abstract}

Keywords:

Fathers, child, feeding, control, pressure to eat, restriction, monitoring, gender 


\section{MATERNAL AND PATERNAL CONTROLLING FEEDING PRACTICES}

\section{WITH MALE AND FEMALE CHILDREN}

Parental use of pressuring feeding practices with their children have been associated with children's lack of self regulation of food intake and failure to respond to internal signals of hunger and satiety (e.g. Johnson \& Birch, 1994), refusal of foods in adulthood that were linked with pressurising feeding practices in childhood (Batsell, Brown, Ansfield \& Paschall, 2002), and inhibition of healthy weight trajectories in infancy (Farrow \& Blissett, in press). Furthermore, restrictive feeding practices have been associated with preference for foods that are restricted (Fisher \& Birch, 1999), eating in the absence of hunger, (Birch, Fisher \& Davison, 2003) and a more negative self evaluation of eating (Fisher \& Birch, 2000).

It is undisputed that mothers tend to be the primary caregivers, and as such tend to be the ones predominantly responsible for feeding their children; for example, in recent studies which have invited parents to provide information regarding their children's eating, between 2 and $8 \%$ of respondents were fathers (Patrick, Nicklas, Hughes \& Morales, 2005; Wardle, Carnell \& Cooke, 2005). Indeed, the majority of research in this area has focussed on maternal feeding practices, despite the fact that paternal factors have been demonstrated to be important determinants of decisions to breastfeed, child body satisfaction, child's engagement in food restricting activities and maternal social support within the feeding interaction (Davison \& Birch, 2001; Field, Camargo, Taylor, Berkey, Roberts \& Colditz, 2001; Olrick, Pianta \& Marvin, 2002; Saarilehto, Keskinen, Lapinleimu, Helenius \& Simell, 2001; Scott, Landers, Hughes \& Binns, 2001; Smolak, Levine \& Schermer, 1998). For example, Smolak, Levine \& Schermer (1999) demonstrated that girls' body esteem was related to their 
fathers' complaints about his weight, and his dieting behaviours were related to his daughter's dieting concerns and behaviours. Furthermore, Olrick, Pianta \& Marvin (2002) demonstrated that maternal marital satisfaction was significantly related to the father's involvement with and responsiveness to his child's mealtime signals.

Whilst maternal factors have generally been found to be more important than paternal factors in the prediction of child eating disturbance (Davison \& Birch, 2001; Wertheim, Mee \& Paxton, 1999), the majority of studies that have included paternal factors in their investigation have found some relationship between paternal attitudes such as body dissatisfaction, paternal behaviours such as dieting, and their child's disturbed eating attitudes and behaviours (Davison \& Birch, 2001; Field et al., 2001; Smolak et al., 1998). Furthermore, in some studies, paternal factors have been shown to add significantly to the impact of maternal factors in the explanation of phenomena such as initiation of dieting (e.g. Huon \& Walton, 2000), body esteem in five year old girls (Davison \& Birch, 2001) and weight concerns and dieting behaviours (Field et al., 2001). Furthermore, it appears that the link between paternal and child attitudes and behaviour may be more specific to the father-daughter relationship than to the father-son relationship (Thelen \& Cormier, 1995), although some studies have found links between father and son's eating attitudes and behaviours (e.g. Field et al., 2001). These studies together emphasise the importance of continued assessment of the role of the father in feeding and eating interactions. However, to date, no research has explicitly compared maternal and paternal control of feeding in non-clinical, preschool boys and girls.

Furthermore, no research to date has examined the relationships between parental unhealthy eating attitudes and the use of controlling feeding practices in both mothers and fathers with their daughters and sons. Maternal eating psychopathology 
has been consistently related to feeding disturbance in children, (e.g. Coulthard, Blissett \& Harris, 2004), and it has been suggested that there may be different motivations for maternal use of controlling feeding practices with male and female children, which may be linked to maternal eating psychopathology (Blissett, Meyer, Farrow, Bryant-Waugh \& Nicholls, 2005). It has been suggested that the links between parental eating concerns and child feeding are more likely to be transmitted from mother to daughter, than through fathers, or to sons (Fisher \& Birch, 1999; Smolak et al., 1999; Wertheim et al., 1999). These differential relationships may depend in part on different social pressures on children to conform to gender stereotypes and on mothers to feed their child in a way which facilitates the achievement of these stereotyped ideals. For example, Birch \& Fisher (1995) hypothesised that the higher amount of control placed upon girls' food intake reflects sex differences in ideal body size and attractiveness, and that it is more acceptable to be a heavy boy than a heavy girl. Furthermore, Ricciardelli \& McCabe (2001) suggested that parents are less likely to encourage boys to lose weight as a result of the differences in societal ideals for weights of boys and girls, and that parents of boys may be more likely to encourage them to gain weight. However, such differences in feeding strategies dependent on child gender remain to be adequately investigated.

Birch \& Davison (2001) describe a model of family environmental influence where child feeding practices of food restriction and pressure to eat are predicted by parent's own eating behaviours, children's current weight status, and parental concern about their child's future risk of overweight. These controlling parental practices are carried out in an attempt to prevent the development of overweight, but conversely reduce the child's opportunity for the development of self regulatory behaviour, thus ultimately inhibiting self regulation of energy intake in the presence of palatable 
foods. Such a model highlights that parent and child BMI should be taken into account in the assessment of the relationship between parental eating and feeding practices. However, whilst some work has suggested that the relationships between parental eating psychopathology and controlling feeding practices are independent of child actual or perceived weight (Tiggeman \& Lowes, 2002), and that maternal and child BMI are unrelated to maternal-child feeding patterns (Faith et al., 2003), others suggest that aspects of controlling feeding practices can explain significant amounts of variance in children's adiposity (e.g. Spruijt-Metz, Lindquist, Birch, Fisher \& Goran, 2002). Therefore, the role of BMI in these relationships warrants further attention.

This study had two main aims. First, we aimed to assess whether mothers' and fathers' controlling feeding practices (pressure to eat, restriction, and monitoring) differed, and whether they varied according to the gender of their child. Second, we aimed to determine whether maternal and paternal unhealthy eating attitudes and BMI were related to controlling child feeding practices, and to examine variation in the patterns of relationships between attitudes and feeding practices dependent on the combination of the gender of parent and child within a dyad. Therefore, it was hypothesised that unhealthy eating attitudes and perceived feeding responsibility would be greater for mothers than fathers. It was also hypothesised that there would be gender differences in the report of controlling feeding practices, with mothers reporting greater controlling feeding practices than fathers, and with mothers and fathers reporting greater restriction and monitoring of their daughters' food intake, and reporting placing greater pressure to eat on their sons. It was also hypothesised that both unhealthy maternal and paternal eating attitudes would be related to more controlling feeding practices, and that these relationships would be particularly 
evident in mother-daughter dyads. We also examined the role of child and parent BMI in these relationships, given their established link with controlling feeding practices.

\section{METHOD}

Participants:

One hundred and eighty eight co-habiting parents of 94 children (aged 12-62 months, mean age 37.7 months, $\mathrm{SD}=12.7,46$ male children, 48 female children) were recruited through private pre-school nurseries within the cities of Birmingham, Coventry and Cambridge, in the UK. Data on SES was not collected but the nurseries catered for primarily professional, well-educated parents in affluent areas. (Previous studies have not found an effect of SES on feeding practice: e.g. Faith et al., 2003; Patrick et al., 2005). All families from each of the nurseries were given questionnaires by nursery staff if they had a child over 1 year of age. Approximately 1000 questionnaires were delivered to nurseries, and in addition to the 188 parents in this study, a further 50 parents (42 mothers and 8 fathers) responded to the questionnaire but their partners failed to participate, and so their data could not be used. The mothers' and fathers' ages ranged from 22 to 53 years, with a mean age of 36.6 years ( $\mathrm{SD}=4.7)$. Mean maternal BMI was $23.6(\mathrm{SD}=4.6)$, mean paternal $\mathrm{BMI}$ was 24.5 ( $\mathrm{SD}=3.0)$. Mean daughters' BMI was $15.8(\mathrm{SD}=1.8)$, and mean sons' BMI was 16.9 $(\mathrm{SD}=2.1)$. BMI scores appear to be slightly lower than the mean BMI scores for three year old English children (16.5 for girls and 17.2 for boys: Health Survey for England, 2004). There were no significant differences between male and female children in age, but male children had significantly greater BMI than female children $(\mathrm{z}=-2.615$, $\mathrm{p}<0.05)$. 
Measures

Eating Disorders Inventory-2 (EDI-2: Garner, 1991)

The EDI-2 is a 91-item measure with higher scores indicating greater levels of pathology. The EDI-2 is divided into eleven subscales, but only the three eating cognition subscales have been used in this study, those of Drive for thinness, Bulimia, and Body dissatisfaction. The EDI-2 has good internal consistency and good testretest reliability, with adequate content, convergent, and discriminant validity (Garner, 1991). It has also been found to be useful and to have acceptable validity and reliability in non-clinical samples (Berman, Lam \& Goldner, 1993; Meyer \& Waller, 1998; Wicks, Siegert \& Walkey, 2004).

The Child Feeding Questionnaire (CFQ: Birch, Fisher, Grimm-Thomas, Markey, Sawyer, \& Johnson, 2001).

The CFQ was used to assess parental perception of feeding responsibility and the feeding practices of monitoring of food intake, restrictive feeding practices, and application of pressure to eat. The CFQ is widely used to assess parental control over child feeding (Carper, Fisher \& Birch, 2000; Fisher, Birch, Smiciklas-Wright \& Picciano, 2000; Fisher, Mitchell, Smiciklas-Wright \& Birch, 2002; Francis, Hofer, \& Birch, 2001), and has been shown to have good validity and reliability (Birch et al., 2001).

Procedure

Nursery staff were asked to distribute questionnaires to parents. Following informed written consent, all measures were completed and returned separately by mothers and fathers, in prepaid envelopes, to the university. Codes were used to 
match the questionnaires when they were returned to the researcher. Parents reported their own and their child's height and weight.

Data analysis

Data were non-normally distributed, therefore non-parametric tests (KruskalWallis tests, Mann-Whitney tests, Spearman's correlations, 1-tailed) were used. Child age and parent age were not significantly correlated with controlling feeding practices, and therefore were not controlled for or examined in further analyses.

\section{RESULTS}

Table 1 about here

The mean EDI scores for females are consistent with those for non-clinical females reported by Berman, Lam and Goldner (1993), and although non-clinical comparison data regarding fathers is limited, the mean EDI scores for non-clinical males in this sample are comparable to those of Meyer and Waller (1998), in their student sample. The mean CFQ scores are broadly comparable to those reported for North American parents of young children (Birch et al., 2001) and slightly higher than those reported for a UK sample of mothers of one-year-old infants (Farrow \& Blissett, 2006). 
Mann-Whitney tests were used to test the hypothesis that unhealthy eating attitudes and perceived feeding responsibility would be greater for mothers than fathers. Table 1 illustrates the means and standard deviations of age, BMI, eating attitude and perceived feeding responsibility data for mothers and fathers. Fathers were significantly older and had significantly higher BMIs than mothers. Mothers reported significantly greater feeding responsibility, drive for thinness and body dissatisfaction than fathers. In percentage terms, $18.1 \%$ of mothers and $0 \%$ of fathers reported that they were always responsible for their children's feeding; $62.8 \%$ of mothers and $4.3 \%$ of fathers reported that they were mostly responsible for their child's feeding; and $15.9 \%$ of mothers and $29.7 \%$ of fathers reported that they were responsible for their children's feeding approximately half the time. Fathers tended to report being seldom responsible (62.8\% vs $3.2 \%$ of mothers) while $3.2 \%$ of fathers (vs. $0 \%$ of mothers) reported never being responsible for their children's eating.

Table 2 about here

Kruskal-Wallis tests were used to test the hypothesis that there would be differences in the report of feeding practices by mothers and fathers with their daughters and sons. Table 2 illustrates the means and standard deviations of controlling feeding practices for parents of male and female children. Post-hoc Mann-Whitney analyses demonstrated that mothers reported significantly higher monitoring than fathers, irrespective of the gender of their child: mothers of girls reported more monitoring than fathers of girls $(\mathrm{z}=-4.45, \mathrm{p}<0.001)$ and fathers of boys $(\mathrm{z}=-5.15, \mathrm{p}<0.001)$, and mothers of boys reported more monitoring than fathers of boys $(\mathrm{z}=-4.70, \mathrm{p}<0.001)$ or 
fathers of girls $(\mathrm{z}=-3.96, \mathrm{p}<0.001)$. Mothers of girls and mothers of boys did not differ in their monitoring of their child's food intake $(z=-.30, p>0.05)$. Fathers of girls and fathers of boys did not differ in their monitoring of their child's food intake $(\mathrm{z}=-1.05$, $\mathrm{p}>0.05)$. There were no differences between mothers and fathers of sons or daughters in their reports of their tendency to restrict foods or pressure their children to eat. We have also presented the correlations between maternal and paternal controlling feeding practices to further elucidate the nature of the relationships between these factors and to allow comparison with other research (see Table 3). Maternal and paternal reports of their use of restriction and monitoring are significantly related, but there was no relationship between maternal and paternal monitoring of their child's food intake.

\section{Links between parental feeding practices and unhealthy eating attitudes}

To test the hypothesis that both unhealthy maternal and paternal eating attitudes would be related to more controlling feeding practices, and that there would be greater links between unhealthy eating attitudes and controlling practices for mothers of girls, 1-tailed Spearman's correlations were carried out between eating attitudes and feeding practices for data split into each of the four parent-child gender combination categories. Table 4 illustrates the correlation matrix for these analyses.

Table 4 about here 
Across the sample as a whole, there were no correlations between parental controlling feeding practices and parental drive for thinness, body dissatisfaction, or parental BMI.

\section{Mothers of girls}

Maternal use of restriction with daughters was significantly correlated with maternal bulimia scores. There were no other significant associations between controlling practices and daughters' BMI or maternal unhealthy eating attitudes.

\section{Mothers of Boys}

There were no correlations between maternal unhealthy eating attitudes with maternal reports of the use of controlling feeding practices with sons. However, maternal use of restriction and pressure to eat were correlated with sons' BMI, with greater restriction in the context of higher BMI, and greater pressure in the context of lower BMI.

\section{Fathers of Girls}

In fathers of girls, there were no significant relationships between paternal unhealthy eating attitudes, child BMI and controlling feeding practices.

\section{Fathers of Boys}

In fathers of boys, there were no relationships between paternal unhealthy eating attitudes with practices of restriction or pressure to eat, nor was the son's BMI related to the use of controlling feeding practices in this sample. However, paternal body dissatisfaction was associated with greater monitoring of son's food intake. 


\section{Differences in magnitude of correlation coefficients}

Finally, to establish whether the correlation coefficients were significantly different depending on the dyad in question, we used a web-based calculation of the difference in magnitude of the correlation coefficients (IFA Services Statistics, 2005). This revealed that the relationship between pressure to eat and BMI in mothers of boys was significantly greater than the equivalent relationship in fathers of boys $(p<0.04)$. Furthermore, the relationship between bulimic symptoms and restriction in mothers of girls was significantly greater than the equivalent relationship in mothers of boys $(\mathrm{p}<0.02)$, fathers of girls $(\mathrm{p}<0.05)$ and fathers of boys $(\mathrm{p}<0.02)$. Finally, the relationship between monitoring and body dissatisfaction in fathers of boys was significantly greater than the equivalent relationship in fathers of girls $(\mathrm{p}<0.03)$.

\section{DISCUSSION}

The study aimed to explore the differences between maternal and paternal eating-related attitudes and feeding practices, and to determine whether maternal and paternal unhealthy eating attitudes were related to controlling child feeding practices in a non-clinical group. Furthermore, the study aimed to examine variation in patterns of relationships between unhealthy eating attitudes and feeding practices dependent on the combination of the gender of parent and child within a dyad. The hypotheses of the study were partially supported. There were significant differences between mothers and fathers in their reports of unhealthy eating attitudes, perceived feeding responsibility and monitoring of child feeding. However, mothers and fathers did not differ in their use of restrictive or pressurising practices. In mother-daughter dyads we found evidence of a relationship between bulimic symptoms and controlling feeding 
practices, whilst fathers with greater body dissatisfaction were more likely to monitor their sons' food intake.

Whilst mothers appear to retain much of the responsibility for feeding their children, and are perhaps therefore more likely be in a position to monitor the food intake of their children, this study found that in this non-clinical, UK sample, mothers were no more likely to report restricting or pressuring feeding practices than fathers. Furthermore, family members tended to report similarly in their use of controlling feeding practices as indicated by the correlations between maternal and paternal reports of both restriction and monitoring. This suggests that in datasets where either parent is invited to complete questionnaires regarding their feeding strategies, the gender of the parent is unlikely to significantly affect the rates of reported controlling feeding practices. However, it may also be suggested that, in the UK, in general, fathers may be less likely to be able to report accurately on their children's eating given their lower rates of responsibility for feeding their children and lower levels of monitoring their children's food intake. It may be advantageous in further work to include a behavioural measure of involvement with feeding interactions (e.g. how many times a week do you prepare food for your child, or eat with your child?), in addition to the use of the perceived feeding responsibility scale, to gain a clearer picture of the levels of involvement of fathers within mealtime settings. Furthermore, it would be interesting to explore whether or not observations of fathers' behaviour within the mealtime setting reflects their reports of their use of restriction or pressure, or whether paternal reports are a reflection of the mother's use of these strategies, particularly for those fathers who report very little involvement in feeding their children. 
The fact that we found no significant differences in parents' use of controlling feeding practices of restriction or pressure to eat with their sons and daughters suggests that children of different genders are not necessarily subject to different levels of controlling feeding practice. Furthermore, whilst mothers' controlling feeding strategies appeared to be linked to their son's BMI, and their daughters' adiposity was not a significant correlate of their use of these strategies, the magnitude of the correlations was not significantly different in this small sample. Further work is required to assess the relationship between feeding strategies and adiposity in male and female children.

Although mothers of girls showed no greater tendency to use controlling feeding practices, these mothers used restrictive feeding practices in the context of reports of their own bulimic symptoms. This finding supports the idea that parental perceptions of their own ability to control their food intake and weight or shape have an impact on their tendency to control their children's food intake, with the hypothesised motivation being extrapolation of their own lack of control around food to their children (Birch \& Davison, 2001; Costanzo \& Woody, 1985). In addition, given that the magnitude of this correlation was significantly greater than the corresponding relationship in any of the other parent-child groups, it could be suggested that this theoretical stance is particularly applicable in the context of maternal attempts at controlling food intake for the prevention of overweight in female children. The relationship between bulimia and restrictive feeding practices was significant only for mothers of daughters but not sons, supporting previous work which has suggested that maternal eating psychopathology is related to controlling feeding practices in mothers of girls but not boys (Tiggemann \& Lowes, 2002; Jacobi, Agras \& Hammer, 2001). The fact that the daughter's BMI was not related to 
maternal use of restriction also suggests that these practices may be exhibited irrespective of the child's current weight status, perhaps as a proactive attempt to prevent the development of overweight, in addition to their use as a method of reducing obesity. This supports other work which has suggested that the relationships between parental eating psychopathology and controlling feeding practices may be independent of child actual or perceived weight (Tiggeman \& Lowes, 2002).

The unhealthy eating attitudes of fathers was not linked to their use of restrictive or pressuring feeding practices with their daughters, and their daughters' BMI did not appear to be related to their use of restriction or pressure to eat. However, high levels of paternal unhealthy eating attitudes were scarce in this sample, and this finding does not imply that paternal unhealthy eating attitudes are not detrimental to eating behaviour or attitudes in pre-school children. Furthermore, whilst fathers' restrictive and pressuring feeding practices with their sons were not related to paternal unhealthy eating attitudes, fathers with greater dissatisfaction with their own bodies were more likely to monitor their son's but not their daughter's food intake, further supporting the idea that parents are more likely to be concerned about their children's food intake when they have their own weight or eating concerns (Birch \& Davison, 2001), and suggesting some gender specificity in this model. Important limitations to this study are that parents' and children's height and weight were assessed though self report, so whilst neither child nor parent height, weight or BMI were significantly correlated with feeding practice in this study, it was impossible to determine the accuracy of their self reports. Furthermore, the remaining data are also entirely based on self report, which may be a potentially biased source of information about eating and mealtimes. Much work has established that parental report of their children's eating tends to be accurate (Whelan \& Cooper, 2000; 
Cooper, Whelan, Woolgar, Morrell \& Murray, 2004), but further observational studies examining the feeding styles of both parents would be advantageous. The response rate to the study was also relatively low, which may suggest that families who responded to the study had greater interest or concern over feeding and eating, but the comparability of reports of controlling feeding practices to prior studies (e.g. Birch et al., 2001) suggests that this was not a significantly greater source of bias in this study than in any other study of child feeding. Another potential source of bias was the relatively educated and affluent recruitment areas that were used within this study, which may be a source of different patterns of familial responsibility for feeding, compared to less privileged areas. The age range of the children included in this study was wide, and whilst child age was not related to the use of control in this small sample, further work with larger, age stratified samples may help to map the type of control over feeding used depending on the age of the child. A further limitation of this study is its small sample size, coupled with the risk of increased type 1 errors due to multiple testing. Therefore, the findings of this study are tentative and preliminary and await confirmation with larger sample sizes and more stringent statistical analyses.

This exploratory study has demonstrated that in this small, non-clinical UK sample, whilst mothers retain significantly more feeding responsibilities than fathers, neither parent was more likely to exert control over feeding, and the child's gender did not make significant difference to their likelihood of being pressured to eat or having restriction imposed upon them. Furthermore, as a whole, these findings tentatively suggest that parental extrapolation of weight concerns may be more explicit in same gender relationships (i.e. father-son relationships and motherdaughter relationships). Whilst much further work is required with larger datasets and 
clinical groups to explore this suggestion fully, we suggest that further examination of the father's role in feeding relationships is warranted. 


\section{References}

Batsell W, Brown A, Ansfield M, \& Paschall G. (2002) "You Will Eat All of That!": A retrospective analysis of forced consumption episodes. Appetite, 38, 211-219.

Berman K, Lam R.W., \& Goldner, E.M. (1993). Eating attitudes in seasonal affective-disorder and bulimia-nervosa. Journal of Affective Disorders, 29, 219225.

Birch, L. L. \& Davison, K. K. (2001). Family environmental factors influencing the developing behavioral controls of food intake and childhood overweight. Pediatric Clinics of North America, 48, 893-907.

Birch, L.L., \& Fisher, J.A. (1995). Appetite and Eating Behavior in Children. Pediatric Clinics of North America, 42, 931-953.

Birch L, Fisher J, \& Davison K. (2003) Learning to overeat: maternal use of restrictive feeding practices promotes girls' eating in the absence of hunger. American Journal of Clinical Nutrition, 78, 215-220.

Birch, L. L., Fisher, J. O., Grimm-Thomas, K., Markey, C. N., Sawyer, R., \& Johnson, S. L. (2001). Confirmatory factor analysis of the Child Feeding Questionnaire: a measure of parental attitudes, beliefs and practices about child feeding and obesity proneness. Appetite, 36, 201-210.

Blissett, J., Meyer, C., Farrow, C., Bryant-Waugh, R., \& Nicholls, D. (2005). Maternal core beliefs and children's feeding problems. International Journal of Eating Disorders, 37, 127-134. 
Carper, J. L., Fisher, J. O., \& Birch, L. L. (2000). Young girls' emerging dietary restraint and disinhibition are related to parental control in child feeding. Appetite, $35,121-129$.

Cooper, P. J., Whelan, E., Woolgar, M., Morrell, J., \& Murray, L. (2004). Association between childhood feeding problems and maternal eating disorder: role of the family environment. British Journal of Psychiatry, 184, 210-215.

Costanzo, P. R. \& Woody, E. Z. (1985). Domain-Specific Parenting Styles and Their Impact on the Childs Development of Particular Deviance - the Example of Obesity Proneness. Journal of Social and Clinical Psychology, 3, 425-445.

Coulthard, H., Blissett, J., \& Harris, G. (2004). The relationship between parental eating problems and children's feeding behavior: a selective review of the literature. Eating Behaviors 5, 103-115.

Davison, K. K. \& Birch, L. L. (2001). Weight status, parent reaction, and selfconcept in five-year- old girls. Pediatrics, 107, 46-53.

Faith, M.S., Heshka, S., Keller, K.L., Sherry, B., Matz, P.E., Pietrobelli, A., Allison, D. (2003). Maternal -Child Feeding Patterns and Child Body Weight: Findings from a population sample. Archives of Pediatric Adolescent Medicine, 157, 926-932.

Farrow, C. \& Blissett, J. (in press). Does maternal control during feeding moderate early infant weight gain? Pediatrics.

Farrow, C. \& Blissett, J. (2006). Is maternal psychopathology related to obesigenic feeding practices at one year? Obesity Research, 13, 1999-2005. 
Field, A. E., Camargo, C. A., Taylor, C. B., Berkey, C. S., Roberts, S. B., \& Colditz, G. A. (2001). Peer, parent, and media influences on the development of weight concerns and frequent dieting among preadolescent and adolescent girls and boys. Pediatrics, 107, 54-60.

Fisher J, \& Birch L. (1999) Restricting access to foods and children's eating. Appetite, 32, 405-419.

Fisher J, \& Birch L (2000). Parents' restrictive feeding practices are associated with young girls' negative self-evaluation of eating. Journal of the American Dietetic Association, 100: 1346.

Fisher, J. O., Birch, L. L., Smiciklas-Wright, H., \& Picciano, M. F. (2000). Breastfeeding through the first year predicts maternal control in feeding and subsequent toddler energy intakes. Journal of the American Dietetic Association, 100, 641646.

Fisher, J. O., Mitchell, D. C., Smiciklas-Wright, H., \& Birch, L. L. (2002). Parental influences on young girls' fruit and vegetable, micronutrient, and fat intakes. Journal of the American Dietetic Association, 102, 58-64.

Francis, L. A., Hofer, S. M., \& Birch, L. L. (2001). Predictors of maternal childfeeding style: maternal and child characteristics. Appetite, 37, 231-243.

Garner DM. (1991) Eating Disorder Inventory- 2 Professional Manual. Odessa, Florida: Psychological Assessment Resources.

Health Survey for England (2004). 
Huon, G.F., \& Walton, C.J. (2000). Initiation of Dieting Among Adolescent Females. International Journal of Eating Disorders, 28, 226-230.

IFA Services Statistics (2005). Available at http://www.fon.hum.uva.nl.

Jacobi, C., Agras, W. S., \& Hammer, L. (2001). Predicting children's reported eating disturbances at 8 years of age. Journal of the American Academy of Child and Adolescent Psychiatry, 40, 364-372.

Johnson S, \& Birch L. (1994) Parents' and children's adiposity and eating style. Pediatrics, 94, 653-661.

Meyer, C. \& Waller, G. (1998). Dissociation and eating psychopathology: Gender differences in a nonclinical population. International Journal of Eating Disorders, 23, 217-221.

Olrick, J. T., Pianta, R. C., \& Marvin, R. S. (2002). Mother's and father's responses to signals of children with cerebral palsy during feeding. Journal of Developmental and Physical Disabilities, 14, 1-17.

Patrick, H., Nicklas, T.A., Hughes, S.O., \& Morales, M. (2005). The benefits of authoritative feeding style: caregiver feeding styles and children's food consumption patterns. Appetite, 44, 243-249.

Ricciardelli, L.A. \& McCabe, M.P. (2001). Children's Body Image Concerns and Eating Disturbance: A Review of the Literature. Clinical Psychology Review, 21, $325-344$. 
Saarilehto, S., Keskinen, S., Lapinleimu, H., Helenius, H., \& Simell, O. (2001). Connections between parental eating attitudes and children's meagre eating: questionnaire findings. Acta Paediatrica, 90, 333-338.

Scott, J. A., Landers, M. C. G., Hughes, R. M., \& Binns, C. W. (2001). Factors associated with breastfeeding at discharge and duration of breastfeeding. Journal of Paediatrics and Child Health, 37, 254-261.

Smolak, L., Levine, M. P., \& Schermer, F. (1998). A controlled evaluation of an elementary school primary prevention program for eating problems. Journal of Psychosomatic Research, 44, 339-353.

Spruijt-Metz, D., Lindquist, C. H., Birch, L. L., Fisher, J. O., \& Goran, M. I. (2002). Relation between mothers' child-feeding practices and children's adiposity. American Journal of Clinical Nutrition, 75, 581-586.

Thelen, M. H. \& Cormier, J. F. (1995). Desire to be Thinner and Weight Control Among Children and Their Parents. Behavior Therapy, 26, 85-99.

Tiggemann, M. \& Lowes, J. (2002). Predictors of maternal control over children's eating behaviour. Appetite, 39, 1-7.

Wardle, J., Carnell, S. \& Cooke, L. (2005) Parental Control Over Feeding and Children's Fruit and Vegetable Intake: How Are They Related? Journal of the American Dietetic Association, 105, 227-232.

Wertheim, E. H., Mee, V., \& Paxton, S.J. (1999). Relationships among adolescent girls' eating behaviors and their parents' weight-related attitudes and behaviors. Sex Roles, 41, 169-187. 
Wicks L., Siegert, R.J., Walkey, F.H. (2004). A confirmation of the eight factor structure of the eating disorders inventory in a non-clinical sample, with New Zealand norms. New Zealand Journal of Psychology, 33, 3-7.

Whelan, E. \& Cooper, P. J. (2000). The association between childhood feeding problems and maternal eating disorder: a community study. Psychological Medicine, 30, 69-77. 
Table 1: Descriptive Statistics and Mann-Whitney analyses for Mothers and Fathers

(Mothers N=94, Fathers N=94)

\begin{tabular}{|l|l|l|l|l|l|}
\hline & $\begin{array}{l}\text { Mothers' } \\
\text { Mean }\end{array}$ & $\begin{array}{l}\text { Mothers' } \\
\text { SD }\end{array}$ & $\begin{array}{l}\text { Fathers' } \\
\text { Mean }\end{array}$ & $\begin{array}{l}\text { Fathers' } \\
\text { SD }\end{array}$ & $\begin{array}{l}\text { Mann- } \\
\text { Whitney }\end{array}$ \\
\hline Parental BMI & 23.62 & 4.63 & 24.47 & 3.05 & $\mathrm{z}=-2.25^{*}$ \\
\hline Parental age & 35.69 & 4.13 & 37.56 & 5.09 & $\mathrm{z}=-2.39^{*}$ \\
\hline $\begin{array}{l}\text { Perceived Feeding } \\
\text { Responsibility }\end{array}$ & 4.09 & .62 & 2.49 & .63 & $\mathrm{z}=-10.86^{* *}$ \\
\hline Drive for thinness & 3.00 & 4.30 & 0.80 & 1.20 & $\mathrm{z}=-2.86^{*}$ \\
\hline Body dissatisfaction & 9.32 & 7.42 & 4.54 & 4.69 & $\mathrm{z}=-4.78^{* *}$ \\
\hline Bulimia & 0.70 & 1.24 & 0.43 & 1.69 & $\mathrm{z}=-2.49$ \\
\hline
\end{tabular}

$* \mathrm{p}<0.01 * * \mathrm{p}<0.0001$ 
Table 2: Mean, (SD), and Kruskal-Wallis Analyses of differences between mothers and fathers of sons and daughters in their feeding practice.

\begin{tabular}{|l|l|l|l|l|l|}
\hline & $\begin{array}{l}\text { Mothers of } \\
\text { Girls }\end{array}$ & $\begin{array}{l}\text { Mothers of } \\
\text { Boys }\end{array}$ & $\begin{array}{l}\text { Fathers of } \\
\text { Girls }\end{array}$ & $\begin{array}{l}\text { Fathers of } \\
\text { Boys }\end{array}$ & $\begin{array}{l}\text { Kruskal- } \\
\text { Wallis }\end{array}$ \\
\hline Restriction & $3.35(.79)$ & $3.31(.81)$ & $3.48(.82)$ & $3.43(.83)$ & 2.10 \\
\hline Pressure to eat & $2.53(.96)$ & $2.83(.98)$ & $2.87(.93)$ & $2.92(.92)$ & 5.94 \\
\hline Monitoring & $4.23(.63)$ & $4.18(.70)$ & $3.40(.96)$ & $3.19(.99)$ & $42.79 * * *$ \\
\hline
\end{tabular}


Table 3: Spearman's correlation coefficients between maternal and paternal feeding practices

\begin{tabular}{|l|l|l|l|}
\hline & $\begin{array}{l}\text { Maternal } \\
\text { restriction }\end{array}$ & $\begin{array}{l}\text { Maternal } \\
\text { pressure to eat }\end{array}$ & $\begin{array}{l}\text { Maternal } \\
\text { monitoring }\end{array}$ \\
\hline $\begin{array}{l}\text { Paternal } \\
\text { restriction }\end{array}$ & $.398^{* * *}$ & .086 & $.256^{* *}$ \\
\hline $\begin{array}{l}\text { Paternal } \\
\text { pressure to eat }\end{array}$ & .015 & $.320^{* *}$ & .053 \\
\hline $\begin{array}{l}\text { Paternal } \\
\text { monitoring }\end{array}$ & .087 & -.003 & .160 \\
\hline
\end{tabular}

$* \mathrm{p}<0.05, * * \mathrm{p}<0.01, * * * \mathrm{p}<0.0001$ 
Table 4: 1 tailed Spearman's Correlations between eating psychopathology, BMI and child feeding practices for mothers and fathers of boys and girls separately

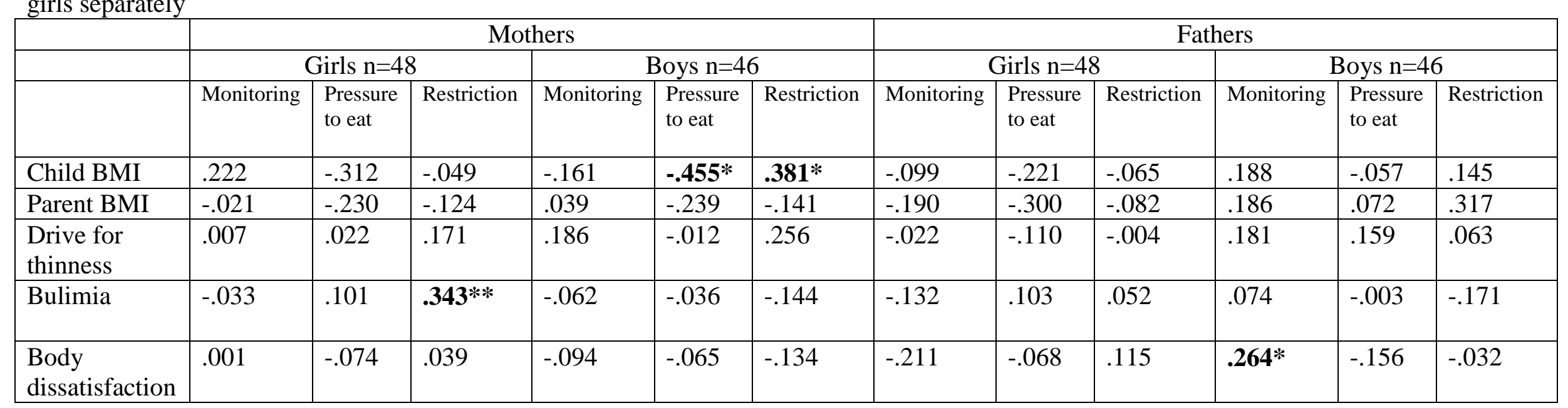

${ }^{*} \mathrm{p}<0.05, * * \mathrm{p}<0.01$ 